\title{
Multi-zone \& multi-compartment model for dynamic simulation of horizontal fluidized bed granulator
}

\author{
Mielke, L. ${ }^{a^{*}}$; Bück, A. ${ }^{\text {; }}$ Tsotsas, E. ${ }^{\text {a }}$ \\ a Thermal Process Engineering, Otto von Guericke University Magdeburg, Germany. \\ ${ }^{\mathrm{b}}$ Institute of Particle Technology, FAU Erlangen-Nuremberg, Germany. \\ *E-mail of the corresponding author: lisa.mielke@ovgu.de
}

\begin{abstract}
Due to the ongoing development and implementation of process control and observation techniques in production processes of particulate products, the research on complexly designed process apparatuses has become of great interest. The work presented in this paper is focused on a model-based study on a multi-chamber horizontal fluidized bed apparatus for fluidized bed layering granulation. The model for the solid phase is extended by a new drying model. Because of the great variety of parameters that influence this complex system a preliminary model-based study on a simplified setup shall show which construction or process parameters influence the product quality.
\end{abstract}

Keywords: fluidized bed granulation; population balance modeling; surface moisture content; drying 


\section{Introduction}

The demands on industrial processes in terms product quality are increasing due to continuing implementation of process control and observation techniques in production processes. In order to meet the quality requirements developed particulate products should consist not only of specified composition, but they should also have defined size distribution and structure. One process widely used for particle size enlargement and coating is the fluidized bed layering granulation process [1]. In earlier works on this issue a multi-zone and multicompartment model for the dynamic simulation of a horizontal fluidized bed spray granulator has been derived and described [2,3]. In this paper the extension of this model by an additional drying model considering the wetted surface area is presented. The novel drying model is integrated in the existing dynamic multi-zone and multi-compartment layering granulation model.

\section{Dynamic model and parameter study}

The full model for the fluidized bed granulation plant includes the dynamic model for the time dependent particle and gas properties in the fluidized bed. The purpose of the fluidized bed model is to calculate quality features of the product, e.g. particle size distribution $n$, particle moisture content $X_{p}$ and relative wetted surface area of the particles $\psi_{p}$, as well as the outlet gas properties such as temperature $T_{g}$ and moisture content $Y_{g}$. A detailed description of the population balance model of the multi-zone and multi-compartment model for spray layering granulation used in this study can be found in $[2,3]$.

Most dynamic drying models for fluidized bed drying and granulation contain mass and energy balances for the description of gas and particle phase. Greatest differences between these models can be found in the calculation of the evaporating mass flow rate or the assumed gas flow pattern. Established drying models for fluidized bed drying and layering granulation are presented in [5, 6, 7]. In this work a novel drying model is presented which takes the size of the initial spray droplets and the geometry of sessile droplets on the particles surface into account. In contrary to common models it allows a consideration of the wetted surface area as transfer area of the heat and mass flow due to evaporation.

In the following the main assumption and simplifications of the regarded model are stated. The particles of each compartment are considered to be ideally mixed. The gas phase in each chamber is also assumed to be ideally mixed. Heat losses to the environment are neglected. The spray droplets are distributed monodipersly. They will exclusively attach to the dry particle surface in a monolayer; overlay of sessile droplets is not considered. Also no percolation or diffusion of surface water into the core particle takes place. The impact area of single droplets on the particle surface as well as the contact area between gas and liquid remains constant during the drying process. Evaporation will only change the number of 
droplets deposited on the particle surface and therefor the total wetted surface area. Sessile droplets have the shape of a ball scraper, therefore three parameter are sufficient to describe the geometry of the sessile droplet, the maximum height of the droplet $h_{d r}$, the contact angle $\theta_{d r}$ and the radius of the impact area $a_{d r}$.

Mass and energy balances for the solid phase, the liquid film and the gas phase for each chamber and compartment have been derived. Heat transfer coefficients between either the dry particle surface and the gas phase and the liquid film and the gas phase are calculated by standard Nusselt correlation for forced convection around a sphere under fluidized bed conditions. Whereas the heat transfer between the liquid film is assumed to be free convection around a sphere and the respective heat transfer coefficient is calculated with $N u=2$. The corresponding transfer areas are determined by the geometric specifications of the sessile droplets and water mass of the film.

To investigate the influence of the separation properties and the novel drying model on the product quality a parameter study is carried out. The model system consists of an apparatus divided in two chambers.

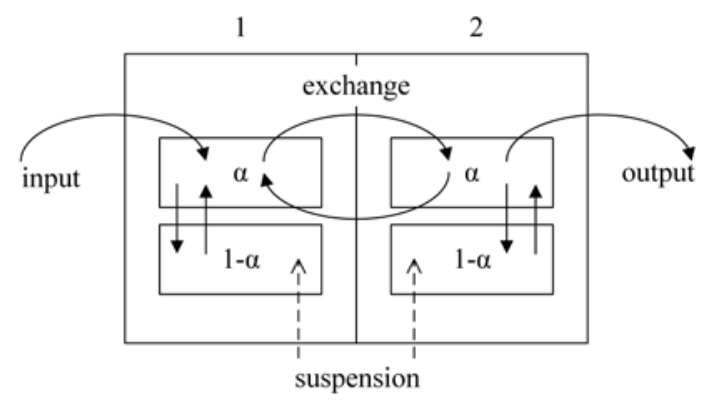

Fig. 1. Schematic representation of the apparatus used in parameter study.

Each chamber is divided into two compartments. The lower compartment is the spray zone, i.e. only particles contained in this compartment are directly in contact with the spray solution or suspension. In the upper compartment, the drying zone, particles are mixed and dried. In presently studied case the particle transport between the chambers can only take place between the upper compartments, the drying zones, of the chambers accounting for the use of overflow weirs.

In order to evaluate the influence of the shape factor of the separation function and the outlet probability on the product quality are studied. To show the dependencies of the drying model water mass flow rate of the spray, the initial droplet diameter, and contact angle of the sessile droplets are varied.

The following particle properties and process conditions at steady-state are observed within the scope of the parameter study. To represent the product particle size distribution particle 
Sauter diameter and standard deviation are chosen. Furthermore the properties of the outlet flow, temperature and moisture content, as well as the product moisture content and the relative wetted surface area are recorded to show the main influence of the introduced drying model.

\section{Results and Discussion}

This section shows selected results of the 14 simulations that have been carried out. In this paper the results for the three influencing factors, $k, \dot{M}_{s u s, w}$ and $d_{d r}$, are shown and discussed in the subsequent paragraphs.

The shape factor of the SF $k$ has an effect on particle Sauter diameter and the particle diameter standard deviation. The model results for particle Sauter diameter and the corresponding standard deviation of particle inlet, chamber 1 and 2, as well as particle outlet for the three examined shape factors for the SF are presented in Figure 2 and 3. Particle processing leads to an increase of particle Sauter diameter and standard deviation of the particle diameter. During the process the particle Sauter increases in each subsequent chamber and reaches the highest value at the outlet. Due to the separation effect of the weirs between the chambers and at the outlet the standard deviation of the particle dimeter decreases on the particles' path through the plant. Increasing the shape factor $k$ leads to more narrow separation functions and results in higher product Sauter diameters and decrease of the standard deviation particle diameter on the particles' path through the plant. The manipulation of the shape factor $k$ shows no significant effect on gas outlet conditions, particle moisture content and wetted particle surface.

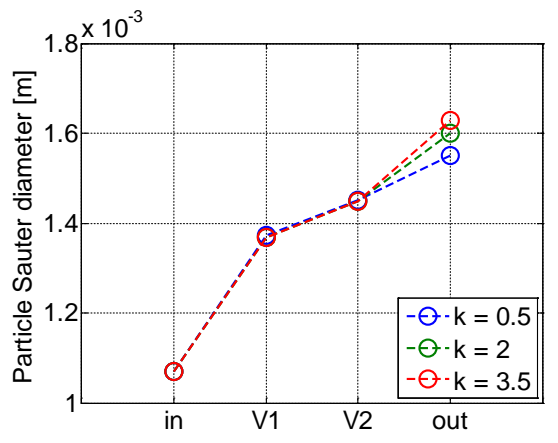

Fig. 2. Particle Sauter diameter for different shape factors of $S F$.

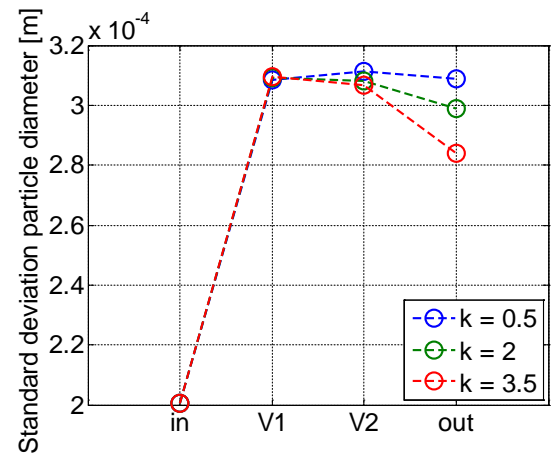

Fig. 3. Standard deviation of particle diameter for different shape factors of SF.

Figure 4 to Figure 7 show the simulation results for outlet gas temperature and outlet gas moisture content, product moisture content and wetted surface area depending on the mass flow rate of water contained in the spray. Increasing the mass flow rate of water in the spray 
decreases the outlet gas temperature and increases the outlet gas moisture content due to the increased evaporation rate.

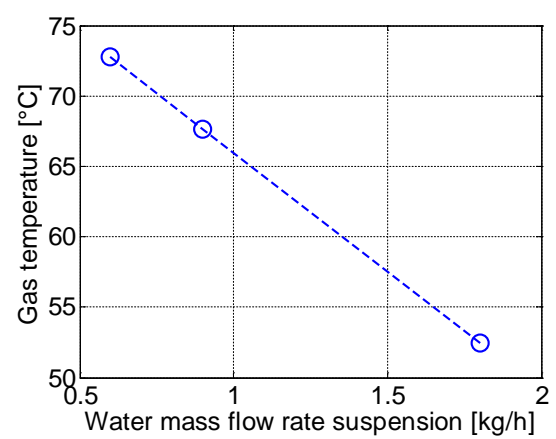

Fig. 4. Gas outlet temperature depending on water mass flow rate.

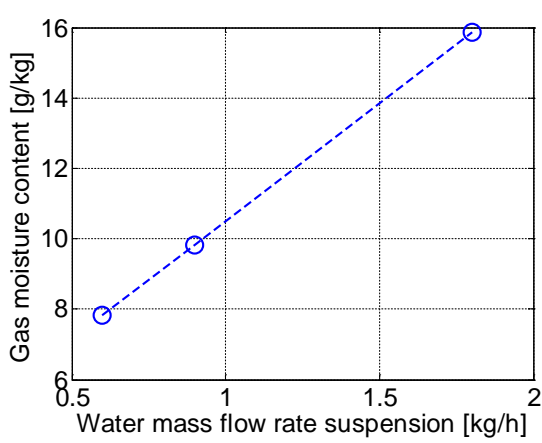

Fig. 5. Gas outlet moisture content depending on water mass flow rate.

Product moisture content and the corresponding wetted surface area are increasing with higher water mass flow rates of the spray. Due to the enhanced relative humidity of the process gas at higher water mass flow rates more water accumulates on the particle surface. Thus both product moisture content and wetted surface area are increasing.

The model results for product moisture and wetted surface area depending on the initial droplet diameter are presented respectively in Figure 8 and Figure 9. An increase of the initial droplet diameter leads to an increase of the product moisture content and wetted surface area. A reduction of the initial droplet diameter increases the contact area between the liquid film and the gas phase which leads to an enhancement of the evaporation rate and consequently to a reduction of particle moisture content and wetted surface area. An effect of the initial droplet diameter on gas outlet conditions cannot be observed.

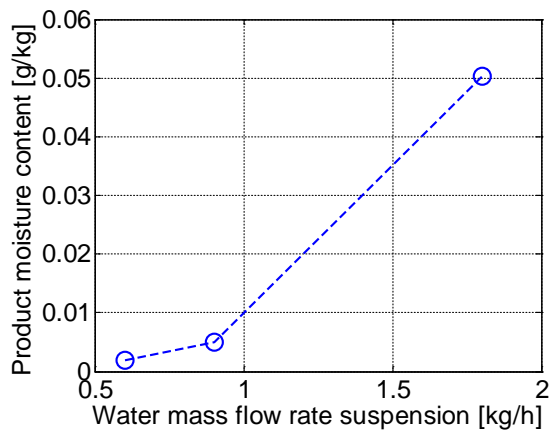

Fig. 6. Product moisture content depending on water mass flow rate.

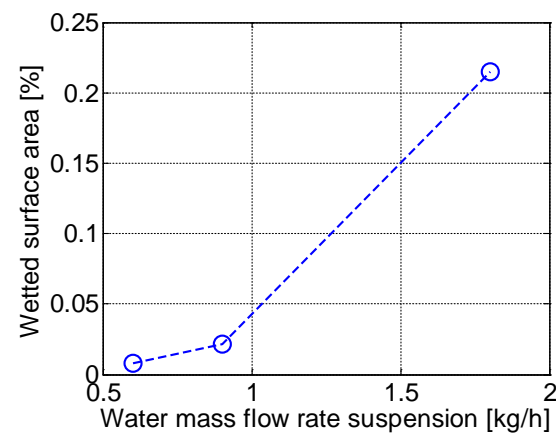

Fig. 7. Wetted surface area depending on water mass flow rate. 


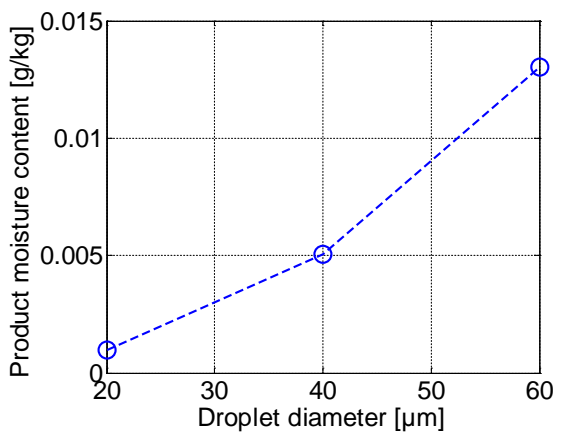

Fig. 8. Product moisture content depending on initial droplet diameter.

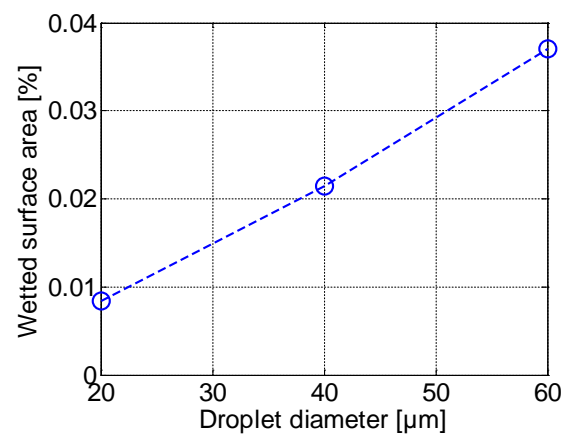

Fig. 9. Wetted surface area depending on initial droplet diameter.

\section{Conclusions}

The aim of the presented preliminary study was to identify what and how the chosen model parameters influence the most important product properties.

Manipulation of the parameters of the separation function only affects the particle growths and has no influence on thermal gas phase and particle properties, such as gas outlet conditions, product moisture content and wetted particle surface. However, a significant effect of the shape factor of the SF on the particle size distributions of the chambers and the product has been observed. Additionally a variation of the thermal process conditions in form of the water mass flow rate of the spray solution has been performed. The introduced water mass flow rate affects the outlet gas properties as well as the product moisture content and wetted surface area. Furthermore the influence of the initial droplet diameter on the product properties has been examined. Results show that the variation of the spray droplet features only influences product moisture content and wetted surface area and has no significant effect on the gas outlet conditions.

\section{Nomenclature}

$\begin{array}{rll}a & \text { Radius of impact area } & \mathrm{m} \\ d & \text { Diameter } & \mathrm{m} \\ h, H & \text { Height } & \mathrm{m} \\ k & \begin{array}{l}\text { Shape factor of separation } \\ \text { function }\end{array} & - \\ l & \text { length } & \mathrm{m} \\ M & \text { Mass } & \mathrm{kg} \\ \dot{M} & \text { Mass flow rate } & \mathrm{kg} \mathrm{s}^{-1}\end{array}$




$\begin{array}{cll}n & \text { Number distribution } & \mathrm{m}^{-1} \\ \dot{n} & \text { Number distribution rate } & \mathrm{m}^{-1} \mathrm{~s}^{-1} \\ N & \text { Number } & - \\ p & \text { Pressure } & \mathrm{bar} \\ P & \text { Discharge probability } & \mathrm{s}^{-1} \\ T & \text { Temperature } & { }^{\circ} \mathrm{C} \\ T_{\text {sep }} & \text { Separation function } & - \\ w & \text { Width } & \mathrm{m}\end{array}$

Greek letters

$\begin{array}{lll}\alpha & \text { Relative size of drying zone } & -1 \\ \theta & \text { Contact angle } & \circ \\ \rho & \text { Density } & \mathrm{kg} \mathrm{m}^{-3} \\ \sigma & \text { Standard deviation } & \mathrm{m} \\ \tau & \text { residence time } & \mathrm{s}\end{array}$

Subscripts

$\begin{array}{ll}0 & \text { Start } \\ 32 & \text { Sauter } \\ \text { bed } & \text { Fluidized bed } \\ \text { d } & \text { diameter } \\ \text { dr } & \text { droplet } \\ \text { g } & \text { Gas phase } \\ \text { in } & \text { inlet } \\ \text { out } & \text { outlet } \\ \text { p } & \text { particle } \\ \text { ref } & \text { reference } \\ \text { sep } & \text { separation } \\ \text { sh } & \text { shell } \\ \text { sus } & \text { suspension } \\ \text { w } & \text { water }\end{array}$




\section{Acknowledgements}

Financial support for this research from German Research Foundation (DFG) as part of the SPP project DynSim 1679 is gratefully acknowledged.

\section{References}

[1] Mörl, L.; Heinrich, S.; Peglow, M. Chapter 2: Fluidized bed spray granulation. In Handbook of Powder Technology, Elsevier, 2007, 21-188.

[2] Meyer, K., Bück, A., Tsotsas, E. Dynamic multi-zone population balance model of particle formulation in fluidized beds. In Procedia Engineering World Congress on Particle Technology 2015, 102, 1456-1465.

[3] Meyer, K., Bück, A., Tsotsas, E. Dynamic modelling of particle formulation in horizontal fluidized beds. Computer Aided Chemical Engineering 2014, 33, 1765-1770

[4] Molerus, O.; Hoffmann, H. Darstellung von Windsichterkurven durch ein stochastisches Modell. Chemical Engineering Technology 1969, 45, 340-344.

[5] Groenewold, H.; Tsotsas, E. A new model for fluid bed drying. Drying Technology 1997, 15 (6-8), 1687-1698.

[6] Burgschweiger, J.; Tsotsas, E. Experimental investigation and modelling of continuous fluidized bed drying under steady-state and dynamic conditions. Chemical Engineering Science 2002, 57 (24), 5021-5038.

[7] Rieck, C.; Homann, T.; Bück, A.; Peglow, M.; Tsotsas, E. Influence of drying conditions on layer porosity in fluidized bed spray granulation. Powder Technology 2015,272, 120 131. 